\title{
LAS GENEALOGÍAS DEL CÓDICE DE RODA
}

\author{
José M. Lacarra
}

Sobre la historia y contenido del códice de Roda existe una abundante bibliografía desde el siglo XVIII hasta nuestros días'. Pero lo que ahora nos interesa especialmente del mismo son las famosas Genealogías, que han sido objeto de diversos estudios, comentarios e interpretaciones; «...si lográramos, decía yo en 1945, averiguar los motivos de esta extraña información genealógica, mucho tendríamos adelantado en nuestro camino ${ }^{2}$.

Ya Traggia, en el siglo XVIII, había aceptado «su antiguiedad y verdad", aunque, no obstante, todavía en el siglo pasado Tomás Ximenez de Embún - que sin duda no conocía los facsímiles de Palomares conservados en la Biblioteca de la Academia de la Historia - las tenía «como uno de tantos entretenimientos monásticos de los siglos XIII o XIV» ${ }^{3}$. Serrano y Sanz hizo notar que su autor había procedido con la mejor buena fe para componer su trabajo, dejando en blanco los nombres de personajes que desconocía - generalmente mujeres, que juegan un papel secundario-, sin duda con la esperanza de ir rellenando los huecos a medida que completara su información; prefirió dejar su trabajo incompleto a llenarlo con nombres falsos of fabulosos ${ }^{4}$.

Por otra parte, como recordaba el profesor Elías Terés, los historiadores árabes mostraron gran interés por las ciencias genealógicas, y no sólo para esclarecer la ascendencia de las tribus de origen oriental que aparecen en la Península, sino sobre personas ilustres de al-Andalus, $y$, lo que ahora puede

1 M.C. Diaz y DiAz, Libros y librerias en la Rioja altomedieval. Logroño 1979, en cuya página 32, nota 16, recoge una rica bibliografía desde 1927, en que se recuperó el códice; a ella habría que añadir también, L. VÁZZUEZ DE PARGA «Algunas notas sobre el Pseudo Methodio y Españas Habis, 26, 1971, p. 143-164.

2J.M. LACARRA, «Texios navarros del códice de Roda» EEMCA, vol. I, Zaragoza 1945, p. 217 .

${ }^{3}$ Ensayo acerca de los origenes de Aragón y de Navarra. Zaragoza, 1878, p. 50.

${ }_{4}^{4} \mathrm{M}$. SERRANO Y SANZ, Noticias y documentos históricos del condado de Ribagorza hasta la muerte de Sancho Garcés III (año 1035). Madrid 1912, p. 160. 
interesarnos más, de familias asentadas en los siglos IX y X en el valle del Ebro, como los Banu-Qasi, los Tuchibíes y los Banu l-Tawil'.

$\mathrm{Y}$ en efecto, no hay más que repasar el «linaje de los muladíes Banu Qasi de la Marca», que nos trasmite Ibm Hazm, inspirado en ellas, para darse cuenta de que las citadas Genealogías de Roda responden al mismo género historiográfico: remontándose al primer ascendiente conocido, se enumeran sus hijos y descendientes, sus mujeres, sus riñas o asesinatos, algunos que apostataron, lugares en que ejercieron su poder, todo muy brevemente y sin ninguna indicación cronológica.

Recientemente el profesor M.C. Díaz y Díaz señalaba la excelente información árabe de que disponía el autor o autores de las distintas piezas del códice, observación que atañe también a las aludidas Genealogías, e insinúa sobre el ambiente andaluz de algún centro monástico de la región del Ebro, a juzgar por otros manuscritos:

El mismo Díaz y Díaz se había ocupado del intercambio de manuscritos entre Cataluña y La Rioja, de un lado, y la monarquía leonesa de otro, manuscritos que eran casi en su totalidad de carácter estrictamente eclesiástico?

En lo que respecta a Cataluña son bien conocidos los contactos entre el mundo árabe y el carolingio. Recordemos lo que dice al-Masudi en su libro Las praderas de oro: que se encontraba en Fostat, en Egipto, el año 336 de la Hégira (947-948), cuando vino a parar a sus manos un escrito compuesto el año 328 de la Hégira (939-940), por Gomar, obispo de Gerona, dedicado a al-Hakam II, hijo de Abd al-Rahman III, con una breve relación de los reyes francos desde Clodoveo a su contemporáneo Luís de Ultramar ${ }^{8}$.

Pero lo que nos revelan las Genealogías es a mi entender algo más interesante: la utilización y conocimiento de estos textos históricos y genealógicos de la comunidad musulmana del Ebro por lo comunidad cristiana, hasta el punto de que mueve a los cristianos a elaborar otros textos genealógicos, de su propia comunidad, calcados de los usuales en la comunidad islámica, lo cual no debía de extrañamos desde el momento en que tenemos abundante información - de origen cristiano y musulmán - acerca de los enlaces matrimoniales entre personajes del Pirineo navarro-aragonés con otros musulmanes de la Ribera de Navarra y de Huesca.

${ }^{5}$ E. TEREs, «Linajes árabes de Al-Andalus», Al-Andalus, XXII, 1957, p. 55: C.PELLAT, «lbn Hazm Bibliographe et apologiste de l'Espagne musulmane», Al-Andalus, XIX, 1954, p. 85-86.

6 M.C. DfAZ Y DLAZ, op. cit., p. 36

7 M.C. Diaz y Diaz, «La transmisión de los textos antiguos en la Península Ibérica en los siglos vu-XIs. Spoleto, Setrimane di Studio XXII, 1974, p. 163 y s.

8 Sobre la obra y su texto véase F. FERNÁNDEZ Y GONZALEZ «Crónica de los reyes francos por Gotmaro II\%, en BAH, Madrid, I, 1879, p. 454-470. 
Ya he señalado en otra ocasión que, si con arreglo a la ley musulmana, las mujeres dadas en matrimonio no tenían por qué aceptar la religión del marido, los hijos de estos matrimonios mixtos debían seguir siempre la ley del padre; $y$ si Onneca, hija de Fortún Garcés, de Pamplona, casó durante el cautiverio de éste en Córdoba, con Abd Allah, futuro emir cordobés - y sería por tanto abuela del califa Abd al-Rahman III- después volvería a casar en tierras de Pamplona y sería la madre de la reina Toda de Pamplona. Algo análogo ocurre en Aragón, en donde Sancha, hija del conde Aznar II, casaría con Muhammad ibn Abd al-Malik, conocido por al-Tawil — walí de Huesca desde 887-con el que tuvo cinco hijos llamados Abd al-Malik, Amrus, Fortunio, Musa y Belasquita. Verdad es que si los hijos de estos matrimonios mixtos deben seguir siempre la ley del padre, con frecuencia se mostraban propicios a cambiar de religion al variar sus inclinaciones políticas.

Ya he mostrado también cómo la «arabización» de estas familias del valle del Ebro sería muy superficial, y que el romance, y tal vez el vascuence, sería en un principio la lengua del hogar, pues sabemos que las mujeres preferidas para ser elegidas como esposas en sus matrimonios eran de estirpe vasca, y que tras la conversión del conde Casius, que daría origen a la familia de los Banu Qasi, conservaron los primogénitos la onomástica vasca hasta la tercera generación?.

Recordemos también cómo todavía no mucho después de componerse las Genealogías, a la caída del Califato, el señor de la taifa de Zaragoza, Mundir, daría muestras de especial habilidad diplomática y buen sentido, según dice el historiador Ibn Hayyan: «Su política con los vecinos reinos cristianos, comenta, fue apaciguadora y amistosa, con el fin de garantizar la seguridad de su pueblo, y en espera del fortalecimiento y la rehabilitación de los musulmanes hasta que, llegado el momento oportuno, pudiera hacer frente a sus enemigos ${ }^{10}$. Para contener la peligrosa vecindad de Sancho el Mayor de Navarra, trató de conciliar a los poderosos condes de Castilla y de Barcelona, uniéndolos en estrecha alianza, y favoreció el matrimonio de Sancha, hija de conde de Castilla, con Berenguer Ramón, hijo del conde de Barcelona, cuyos esponsales tuvieron lugar en Zaragoza ante una concurrida asistencia de cristianos y musulmanes.

Y, no olvidemos, finalmente, que el Ebro seguía siendo navegable, y, por tanto, ruta comercial y de viajeros, en el siglo X, desde Varea (la Rioja) hasta Tortosa (Tarragona), lo mismo que en la época de Plinio ${ }^{11}$.

${ }^{9}$ F. DELA GRANJA, «La Marea Superior en la obra de al-Udrix, en EEMCA, VIII, 1967. p. 447-545, núm. 171 de Al-Udri. Para otros extremos expuestos en el texto, véase J.M. LACARRA, Historia polftica del reino de Navarra desde los origenes hasta su incorporación a Castilla, I, p. 86 y s.

${ }^{10}$ MAHMUD ALI MAKKI, «La España cristiana en el diwan de Ibn Darrays, Bol. Acad. Buenas Letras de Barcelona, XXX, 1963-1964, p. 92.

11 J.M. LACARRA, «Acerca de las fronteras en el valle del Ebro (siglos VIII-XII)s, En la España medieval. Estudios dedicados al profesor D. Julio González Madrid 1981. p. 181-191. 
En resumen, las llamadas Genealogías de Roda son un calco, como literatura histórica, de las obras genealógicas tan frecuentes en el mundo musulmán; esta literatura de genealogías tuvo también sus cultivadores entre los musulmanes del valle del Ebro, con referencia a las familias más importantes que dominaron las ciudades del mismo, familias - como hemos visto - intimamente emparentadas con otras familias cristianas de los territorios libres. Conocido el intercambio de manuscritos cristianos entre los territorios de Castilla y León con Cataluña, no es de extrañar la existencia de una literatura cristiana en el valle del Ebro, bajo dominio musulmán, fruto de la convivencia.

De aquí nuestra conclusión de que las Genealogías de Roda son un género historiográfico que se introduce en el reino de Pamplona a fines del siglo X, cuya corte en esas fechas estaba instalada en la villa de Nájera. 